\title{
Experimental Investigation of Energy Consumption for the Process of Initial Heating of a Substrate to the Fermentation Temperature
}

\author{
Zablodskiy M.M., Spodoba M.O., Spodoba O.O. \\ National University of Life and Environmental Sciences of Ukraine, \\ Kyiv, Ukraine
}

\begin{abstract}
The aim of the work is to experimentally study the energy consumption for the process of initial heating of the substrate to the fermentation temperature in order to increase the energy efficiency of the biogas formation process. To achieve the goals set, a preparation and a series of experimental studies of the indicators of energy consumption for the process of initial heating of the substrate to the fermentation temperature were carried out. The working hypothesis is that the use of a heating cable built into the stirrer paddles reduces the energy costs for the process of initial heating of the substrate, increasing thus the energy efficiency of the biogas production. The most important result of the study was to obtain the dependences of the temperature change in the heating cable, substrate, reactor walls and energy consumption for heating and mixing during the initial heating of the substrate. The significance of the research results presented in the work lies in the fact that when using a heating cable built into the stirrer paddles, the process of initial heating of the substrate to the fermentation temperature occured faster on average by 16 minutes, and the amount of energy spent was also decreased on average by $6.6 \%$ for heating and $5.3 \%$ for mixing the substrate in a 40 -liter biogas reactor. The implementation of the data obtained experimentally increased the energy efficiency of biogas production and the profitability of further processing of biogas into heat and electricity.
\end{abstract}

Keywords: experimental study, initial heating of the substrate, energy consumption, energy efficiency, profitability, organic waste, digestion temperature.

DOI:https://doi.org/10.52254/1857-0070.2022.1-53.07

UDC: 62-523.6

\section{Studiu experimental al consumului de energie la încălzirea inițială a substratului până la temperatura de fermentare}

Zablodskiy M.M. ${ }^{\text {, }}$, Spodoba M.O. ${ }^{1}$, Spodoba O.O. ${ }^{1}$

${ }^{1}$ Universitatea Națională a resurselor biologice și managementului naturii a Ucrainei, Kyev, Ucraina

Rezumat. Scopul lucrării este cercetarea experimentală a consumului de energie pentru procesul de încălzire inițială a substratului până la temperatura de fermentație pentru a crește eficiența energetică a procesului de formare a biogazului și rentabilitatea procesării ulterioare în energie termică şi electrică. Pentru atingerea obiectivelor stabilite au fost soluționate problemele următoare: a fost formulată abordarea metodologică pentru efectuarea cercetărilor experimentale; a fost confecționată instalația experimentală a reactorului de biogaz cu sistem electro-termo-mecanic cu dirijare automată pentru amestecarea și încălzirea substratului; au fost cerrcetați experimental indicii de consum de energie pentru procesul de încălzire inițială a substratului până la temperatura de fermentare; a fost efectuată prelucrarea, analiza și compararea datelor experimentale obținute. Cel mai important rezultat al studiului este obținerea dependențelor variației de temperatură a cablului de încălzire, a substratului, a pereților reactorului și a consumului de energie asupra încălzirii și amestecării pentru timpul încălzirii inițiale a substratului în instalația de biogaz pusă în funcțiune. Semnificația rezultatelor cercetării prezentate în lucrare constă în faptul că, prin utilizarea unui cablu de încălzire încorporat în paletele mixerului, procesul de încălzire inițială a substratului până la temperatura de fermentație are loc mai rapid, și conform celor trei iterații de cercetare se află în diapazonul 14-18 minute, ce este în medie egal cu 16 minute și, de asmenea, o reducere a cantității de energie cheltuită ce constituie 5,8\%-7,4\% pentru încălzire și 4,7-5,9\% pentru amestecare a substratului în reactorul biogazului cu un volum de 40 de litri. În rezultat, valoarea medie a consumului de energie constituie $6,6 \%$ pentru încălzire și 5,3\% pentru amestecarea substratului.

Cuvinte-cheie: studiu experimental, încălzirea inițială a substratului, consumul de energie, eficiența energetică, rentabilitatea, deșeurile organice, temperatura de digestie. 


\section{Экспериментальное исследование затрат энергии на процесс первоначального нагрева субстрата до температуры брожения \\ Заблодский Н.Н. ${ }^{1}$, Сподоба М.А. ${ }^{1}$, Сподоба А.А. ${ }^{1}$ \\ ${ }^{1}$ Национальный университет биоресурсов и природопользования Украины, Киев, Украина} Аннотация. Целью работы является экспериментальное исследование расхода энергии на процесс начального нагрева субстрата до температуры сбраживания для повышения энергетической эффективности процесса образования биогаза и рентабельности дальнейшей переработки в тепловую и электрическую энергии. Для достижения поставленных целей решены следующие задачи: разработан методологический подход для проведения экспериментальных исследований; изготовлена экспериментальная установка биогазового реактора с электротепломеханической системой с автоматическим управлением для перемешивания и подогрева субстрата; экспериментально исследованы показатели расхода энергии на процесс начального нагрева субстрата до температуры сбраживания; проведена обработка, анализ и сопоставление полученных экспериментальных данных. Рабочая гипотеза экспериментальных исследований заключается в том, что использование нагревательного кабеля, встроенного в лопасти мешалки, обеспечит снижение энергетических затрат на процесс начального нагрева субстрата до температуры сбраживания, повысив таким образом энергоэффективность биогазового производства. Наиболее важный результат исследования заключается в получении зависимостей изменения температуры нагревательного кабеля, субстрата, стенок реактора и потребления энергии на нагрев и перемешивание за время начального нагрева субстрата в действующей биогазовой установке. Значимость приведенных в работе результатов исследования заключается в том, что при использовании нагревательного кабеля, вмонтированного в лопасти мешалки, процесс начального нагрева субстрата до температуры сбраживания происходит быстрее, и согласно 3 повторениям исследований находиться в диапазоне 14-18 минут, что в среднем равно 16 минутам, а также достигается снижение количества затраченной энергии которая составляет 5,8-7,4 \% на подогрев и 4,7-5,9 \% на перемешивание субстрата в биогазовом реакторе объемом 40 литров. В результате, среднее значение затраченной энергии составляют $6,6 \%$ на подогрев и 5,3\% на перемешивание. Приведенные в работе данные могут использоваться при проектировании и модернизации систем перемешивания и подогрева субстрата в биогазовых реакторах.

Ключевые слова: экспериментальное исследование, начальный нагрев субстрата, расход энергии, энергоэффективность, рентабельность, органические отходы, температура сбраживания.

\section{ВВЕДЕНИЕ}

Биогазовые технологии играют важную роль в формировании современной энергетической системы мира, поэтому, внимание к их энергоэффективности повышено.

Увеличение фермерских и сельскохозяйственных угодий вместе с ростом поголовья скота приводит к накоплению растительных и животных отходов [1]. Это подталкивает население к поиску альтернативных способов утилизации и переработки отходов, так как системы консервации являются источниками вредных выбросов метана и оксидов азота [2-4].

Такая ситуация приводит к загрязнению окружающей среды, усилению изменений климата и парникового эффекта, что делает актуальными теоретические и практические исследования в области возобновляемых источников энергии [5].
Технологии возобновляемых источников энергии становятся все более конкурентоспособными с точки зрения затрат, но многим странам все еще приходится разрабатывать схемы государственной поддержки, помогающие увеличить их долю $[5,6]$.

Наибольшее распространение при утилизации бытовых и промышленных органических отходов, сточных вод получила анаэробная очистка в специальных емкостях - биогазовых реакторах.

На сегодняшний день утилизация органических отходов на биогазовых установках является одним из самых передовых, экологически и экономически эффективных решений для производства энергии из органических отходов в виде биогаза. Об этом свидетельствует, множество научных исследований, направленных на повышение выхода биогаза и выработки 
электроэнергии на биогазовых установках [7$12]$.

После очистки биогаза можно получить биометан, который может заменить природный газ для использования, как для собственных нужд, так и для производства тепла и электроэнергии.

Побочным эффектом ферментации органических отходов в биогазовых реакторах является получение ценных экологически чистых удобрений.

Процесс анаэробного брожения органических отходов в биогазовом реакторе занимает длительное время, поэтому одними из основных способов интенсификации производства биогаза является перемешивание и нагрев органических отходов в процессе анаэробного брожения $[13,14]$.

Энергоэффективность производства биогаза зависит от величины затрат энергии на процессы интенсификации.

Согласно исследованиям приведенным в работах [13-16], на энергетические затраты смесительного устройства существенное влияние оказывают его геометрические размеры и учёт задачи перемешивания органических отходов.

Trad Z., Fontaine J. [17] провели сравнительный анализ трёх методов перемешивания и определили, что уровень энергии затраченной на перемешивание при использовании механической мешалки был самым низким. Кроме того, механическое перемешивание способствует образованию однородности вещества при меньшем времени перемешивания, особенно это заметно в жидкостях с высокой концентрацией органического вещества. Поэтому, с точки зрения энергосбережения наиболее перспективным оборудованием для интенсификации процесса ферментации органических отходов являются биогазовые реакторы с механическими мешалками $[15$, 17-19]. Об этом свидетельствует интенсивное развитие механических технологий перемешивания субстратов в Европе и Азии $[15,18,19]$.

При создании системы перемешивания органических отходов в биогазовом реакторе необходимо использовать механическую мешалку с наиболее рациональным соотношением площади проекции на перемешиваемое вещество и энергии, затрачиваемой на процесс перемешивания.
Температурный режим и равномерность распределения температурного поля по объему субстрата в биогазовом реакторе оказывают существенное влияние на интенсивность процесса анаэробного брожения [20].

В работах зарубежных и отечественных ученых, встречаются различные системы для перемешивания и подогрева сырья, используемые в процессе анаэробной ферментации последнего, в биогазовых реакторах [7, 12-24].

Согласно исследованиям существующей системы подогрева субстрата с помощью водяной рубашки, на нагрев воды в котельной требуется приблизительно $30-40 \%$ биогаза от общего количества произведенного биогаза [7].

Нагрев субстрата электрическими нагревателями является наиболее эффективным, так как требуемая мощность относительно невелика [24].

Однако из-за возможного прилипания субстрата к поверхности стационарного нагревателя снижается равномерность распределения тепла в объеме субстрата.

$\begin{array}{lcr}\text { Проведенные } & \text { ранее } & \text { исследования } \\ \text { свидетельствуют } & \text { об } & \text { эффективности } \\ \text { бъъддинения } & & \text { механических }\end{array}$
перемешивающих устройств с электрическими нагревателями в одном электротермомеханическом устройстве для перемешивания и нагрева субстрата в биогазовом реакторе.

В работе биогазового реактора выделяют три основных этапа: процесс начального нагрева субстрата до температуры брожения; охлаждение субстрата до температуры включения подогрева; поддержание стабильной температуры анаэробного брожения.

Поэтому, утверждать об энергетической эффективности системы интенсификации производства биогаза возможно только на основании результатов проведенных теоретических и практических исследований затрат энергии на каждую из этих стадий.

Процесс начального нагрева субстрата до температуры брожения характеризуется большими энергетическими затратами, так как загруженный органический субстрат имеет начальную температуру ниже температуры анаэробного процесса брожения. 
На сегодняшний день, большинство стран мира покрывают свои потребности в энергии за счет импорта энергетических ресурсов из стран, которые потребляют меньше энергии, чем производят.

Нестабильность энергетических рынков затрудняет прогнозирование изменения цен, что, в свою очередь, вызывает неуверенность в будущем и нестабильность энергетической политики.

Учитывая вышеизложенное, а также то, что энергоносители и энергетические тарифы являются основными факторами, определяющими устойчивое развитие экономики, теоретическое и практическое изучение, а также, создание энергетически эффективных систем интенсификации процесса анаэробного брожения органических отходов является актуальным вопросом в любой стране мира.

Цель работы - экспериментальное исследование энергетических затрат на процесс начального нагрева субстрата до температуры брожения с целью повышения энергетической эффективности процесса образования биогаза, рентабельности его дальнейшей переработки в тепловую и электрическую энергии.

\section{I. МЕТОДИКА ИССЛЕДОВАНИЙ}

Большое распространение в качестве систем подогрева субстрата в биогазовых реакторах имеет «классическая» система электрического нагрева - при размещении электрического нагревательного кабеля на наружной стенке реактора.

Однако, согласно ранее проведенными нами, в 2020-2021 годах, теоретическими исследованиями альтернативных вариантов систем подогрева субстрата в биогазовом реакторе, было определенно «рациональную» систему электрического обогрева - при расположении нагревательного кабеля в лопастях двухъярусной лопастной механической мешалки.

Теоретические исследования показали уменьшение длительности протекания процессов перемешивания и подогрева субстрата в биогазовом реакторе при объединении перемешивающих механических электрическими нагревателями в одном электротермомеханическом устройстве.

Система уравнений, описывающая, динамику изменения температуры объектов при разных вариантах электрического подогрева субстрата в биогазовых реакторах имеет следующий вид:

- для «классической» системы обогрева:

$$
\begin{aligned}
& \frac{d T_{c n}}{d \tau}=\frac{P \cdot \xi+k_{u 3} \cdot F_{c n} \cdot\left(T_{u 3}-T_{c n}\right)}{c_{c n} \cdot m_{c n}} ; \\
& \frac{d T_{u 3}}{d \tau}=\frac{1}{c_{u 3} \cdot m_{u 3}} \cdot\left(k_{u 3} \cdot F_{c n} \cdot\left(T_{c n}-T_{u 3}\right)+\right. \\
& \left.+k_{c} \cdot F_{\kappa} \cdot\left(T_{c}-T_{\text {из }}\right)+k_{\text {пот }} \cdot F_{\kappa . \text { пот }} \cdot\left(T_{\text {окр }}-T_{\text {из }}\right)\right) \text {; }
\end{aligned}
$$

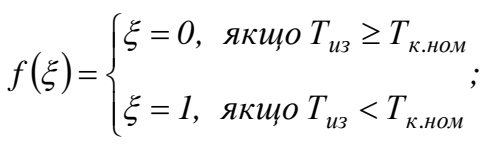

$$
\begin{aligned}
& Q_{\text {нагр }}=\frac{\pi \cdot\left(T_{\text {из }}-T_{\text {суб }}\right)}{R_{l}+R_{2}} \cdot H_{\kappa} ; \\
& \frac{d T_{c}}{d \tau}=\frac{1}{c_{p} \cdot m_{p}} \cdot\left(k_{c} \cdot F_{\kappa} \cdot\left(T_{u 3}-T_{c}\right)+\right. \\
& \left.+\alpha_{l} \cdot F_{c} \cdot\left(T_{c y \sigma}-T_{c}\right)+k_{l} \cdot\left(H_{1}-H_{K}\right) \cdot\left(T_{H}-T_{c}\right)\right) ; \\
& \frac{d T_{c y \sigma}}{d \tau}=\frac{Q_{\text {нарр }}+\alpha_{1} \cdot F_{c} \cdot\left(T_{c}-T_{c y \sigma}\right)}{c_{c y \sigma} \cdot m_{c y \sigma}} .
\end{aligned}
$$

- для «рациональной» системы обогрева:

$$
\frac{d T_{c n}}{d \tau}=\frac{P \cdot \xi+k_{u 3} \cdot F_{c n} \cdot\left(T_{u 3}-T_{c n}\right)}{c_{c n} \cdot m_{c n}} ;
$$

$$
\begin{aligned}
& \frac{d T_{u 3}}{d \tau}=\frac{1}{c_{u 3} \cdot m_{u 3}} \cdot\left(k_{u 3} \cdot F_{c n} \cdot\left(T_{c n}-T_{u 3}\right)+\right. \\
& \left.+k_{л} \cdot F_{\kappa l} \cdot\left(T_{л}-T_{u 3}\right)\right) \text {; } \\
& f(\xi)=\left\{\begin{array}{l}
\xi=0, \text { якщо } T_{\text {из }} \geq T_{\text {к.ном }} \\
\xi=1, \text { якщо } T_{\text {из }}<T_{\text {к.ном }}
\end{array} ;\right.
\end{aligned}
$$$$
\frac{d T_{\Omega}}{d \tau}=\frac{1}{c_{\Omega} \cdot m_{л}} \cdot\left(k_{л} \cdot F_{\kappa 1} \cdot\left(T_{u 3}-T_{л}\right)+\right.
$$$$
\left.+\alpha_{2} \cdot F_{n} \cdot\left(T_{c y \sigma}-T_{\pi}\right)\right) \text {; }
$$

$$
Q_{\text {нагр }}=\frac{T_{u 3}-T_{c y \sigma}}{R_{3}+R_{4}} \cdot\left(F_{l} \cdot n_{1}\right) ;
$$

$$
\frac{d T_{c y \sigma}}{d \tau}=\frac{1}{c_{c y \sigma} \cdot m_{c y \tilde{\sigma}}} \cdot\left(Q_{\text {нагр }}+\right.
$$

$$
+\alpha_{2} \cdot\left(F_{n} \cdot n_{l}\right) \cdot\left(T_{n}-T_{c y \tilde{\sigma}}\right)+
$$$$
\left.+k_{c} \cdot\left(F_{c}+F_{\text {oсH }}\right) \cdot\left(T_{c}-T_{c y \sigma}\right)\right) ;
$$$$
\frac{d T_{c}}{d \tau}=\frac{1}{c_{p} \cdot m_{p}} \cdot\left(k_{c} \cdot\left(F_{c}+F_{o c h}\right) \cdot\left(T_{c y \sigma}-T_{c}\right)+\right.
$$

$\left.+k_{l} \cdot H_{l} \cdot\left(T_{H}-T_{c}\right)\right)$. 
где: $\quad P \quad-$ мощность приложена к электрическому нагревательному кабелю, Вт; $\tau$ - время, с; $m_{c n}$ - масса спирали нагревательного кабеля, кг; $c_{c n}$ - удельная теплоемкость спирали электрического нагревательного кабеля, Дж/(кг. $\left.{ }^{0} \mathrm{C}\right) ; T_{c n}-$ температура спирали электрического нагревательного кабеля, ${ }^{0} \mathrm{C} ; \quad k_{u з} \quad-$ коэффициент теплопередачи через толщину изоляции электрического нагревательного кабеля, Вт $/\left(\mathrm{M}^{2} \cdot{ }^{0} \mathrm{C}\right) ; F_{c n}$ - площадь спирали электрического нагревательного кабеля, м²; $\xi-$ коэффициент регулировки; $T_{\text {из }}-$ температура изоляции электрического нагревательного кабеля, ${ }^{0} \mathrm{C} ; m_{u з}$ - масса изоляции электрического нагревательного кабеля, кг; $c_{u з}-$ удельная теплоемкость изоляции электрического нагревательного кабеля, Дж/(кг. $\left.{ }^{0} \mathrm{C}\right) ; \quad k_{c}-$ коэффициент теплопередачи в толщине стенки биогазового

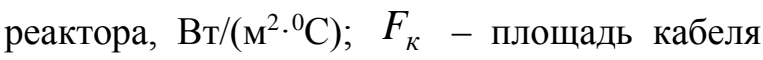
прижатого к стенке реактора, м $^{2} ; T_{c}-$

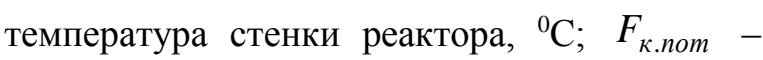
площадь электрического нагревательного кабеля, отдающего энергию через изолирующий материал и защитный кожух в окружающую среду, м $^{2} ; T_{\text {окр }}$ - температура окружающей среды, ${ }^{0} \mathrm{C} ; k_{\text {nот }}-$ коэффициент теплопередачи в окружающую среду, Вт/( $\left.{ }^{2} \cdot{ }^{0} \mathrm{C}\right) ; \quad T_{\text {к.ном }}-$ номинальная температура поверхности электрического нагревательного кабеля, ${ }^{0} \mathrm{C} ; m_{p}-$ масса реактора, кг; $c_{p}$ - удельная теплоемкость материала из которого изготовлен реактор, Дж/(кг $\left.{ }^{0} \mathrm{C}\right) ; \alpha_{1}-$ коэффициент теплоотдачи от стенки биогазового реактора к объему субстрата, Вт/(м $\left.{ }^{2}{ }^{0} \mathrm{C}\right) ; \quad F_{c}-$ внутренняя площадь стенки биогазового реактора, м $^{2}$; $T_{\text {суб }}$ - температура субстрата, ${ }^{0} \mathrm{C} ; k_{l}-$ линейный коэффициент теплопередачи в окружающую среду, Вт/(м. $\left.{ }^{0} \mathrm{C}\right) ; H_{1}$ - высота биогазового реактора, м; $H_{\kappa}$ - суммарная высота кабеля смонтированного на наружной стенке биогазового реактора, м; $m_{\text {суб }}$ - масса субстрата, кг; $c_{c y б}$ - удельная теплоемкость субстрата, Дж/(кг. $\left.{ }^{0} \mathrm{C}\right) ; \quad Q_{\text {нагр }} \quad-$ тепловой поток от электрического нагревательного кабеля к субстрату, Вт; $R_{1}$ - термическое сопротивление цилиндрической стенки биогазового реактора, м $^{\circ} \mathrm{C} / \mathrm{BT} ; \quad R_{2}-$ термическое сопротивление теплоотдаче от цилиндрической стенки реактора к объему субстрата, м. ${ }^{0} \mathrm{C} / \mathrm{BT} ; k_{л}-$ коэффициент теплопередачи от внутренней к наружной стенке лопасти, Вт/( $\left.{ }^{2.0} \mathrm{C}\right) ; F_{\kappa l}-$ площадь электрического нагревательного кабеля, из которого теплота отдается через стенку лопасти к субстрату, м²; $T_{л}$ - температура лопасти, ${ }^{0} \mathrm{C} ; m_{л}$ - масса лопасти, кг; $c_{л}-$ удельная теплоемкость материала из которого изготовлена лопасть, Дж/(кг. $\left.{ }^{0} \mathrm{C}\right)$; $\alpha_{2}$ - коэффициент теплоотдачи от наружной стенки лопасти к объему субстрата, $\mathrm{BT} /\left(\mathrm{M}^{2} \cdot{ }^{0} \mathrm{C}\right) ; \quad F_{л}-$ площадь поверхности лопасти, м $^{2} ; \quad R_{3}-$ термическое сопротивление теплопроводности от внутренней к наружной стенке лопасти, м. ${ }^{0} \mathrm{C} / \mathrm{BT} ; R_{4}-$ термическое сопротивление теплопроводности в объеме субстрата, $\mathrm{M} \cdot{ }^{0} \mathrm{C} / \mathrm{BT} ; \quad n_{1}-$ количество лопастей механической мешалки, шт; $F_{\text {осн }}$ - площадь основания биогазового реактора, $\mathrm{M}^{2}$;

В 2020-2021 годах с использованием выше представленных систем уравнений (1) и (2), нами было проведено и опубликовано ряд теоретических исследований, однако, утверждать, о энергетической эффективности технологических процессов интенсификации биогазового производства, возможно только на основании проведенных комплексных теоретических и практических исследований затрат энергии. С этой целью, нами было проведено экспериментальное исследование энергетических затрат на процесс начального нагрева субстрата до температуры брожения. Для анализа воспроизводимости результатов исследований опыты проводили в 3-х повторениях.

Экспериментальное исследование энергетических затрат на процесс начального нагрева субстрата до температуры анаеробного брожения проводили на изготовленной экспериментальной установке 
- $\quad$ биогазовом

реакторе

электротермомеханической системой и автоматическим управлением процессом перемешивания и нагрева субстрата. Внешний вид экспериментальной установки показан на рис. 1.

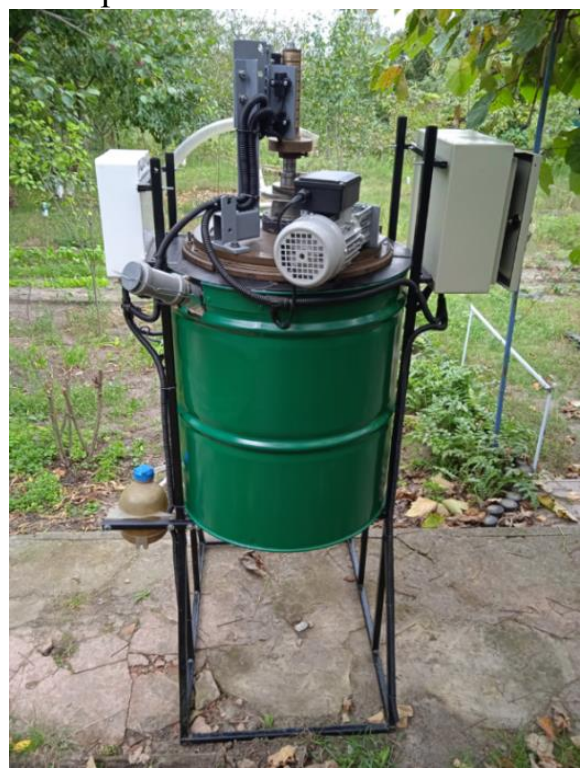

Рис. 1. Внешний вид экспериментальной биогазовой установки. ${ }^{1}$

В ходе экспериментальных исследований был использован сравнительный анализ двух систем электрообогрева: «классической» - с расположением нагревательного кабеля на

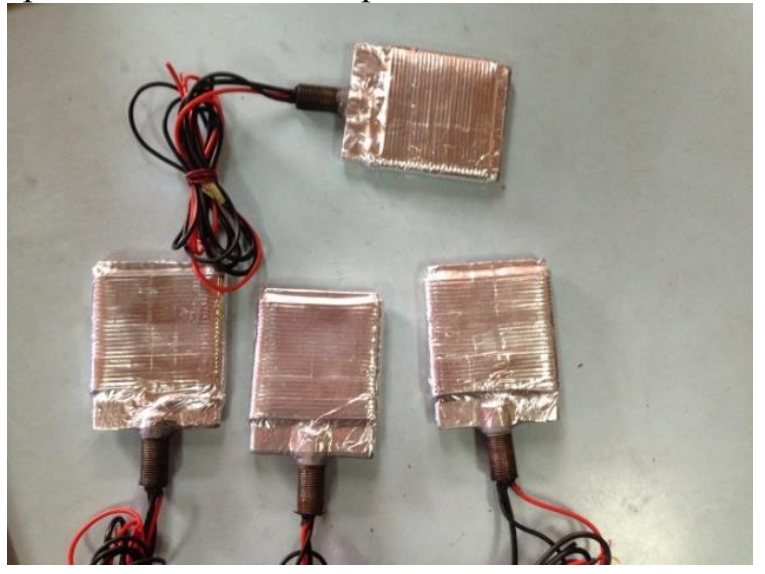

a) внешней стенке реактора, рис. 2 и «рациональной» - при расположении нагревательного кабеля в лопастях двухъярусной лопастной мешалки, рис. 3.

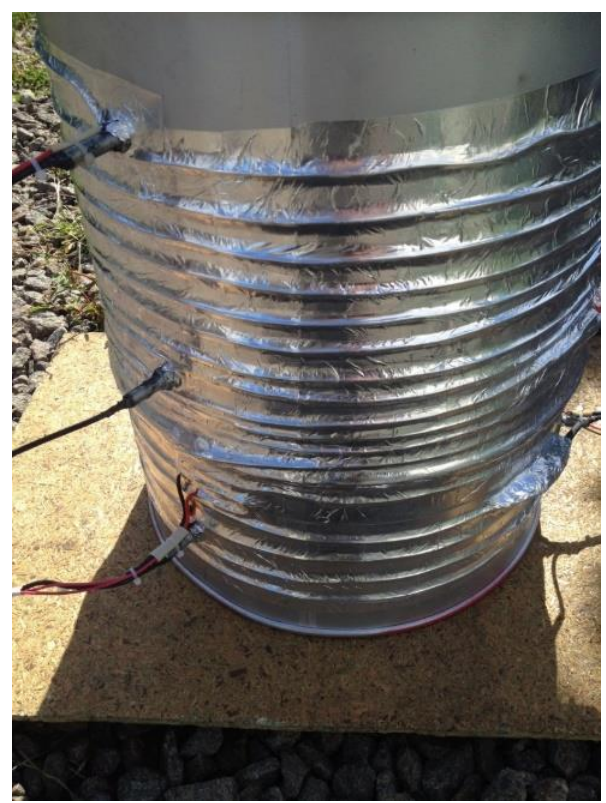

Рис. 2. Электрический нагревательный кабель, уложенный на наружную стенку биогазового реактора. ${ }^{2}$

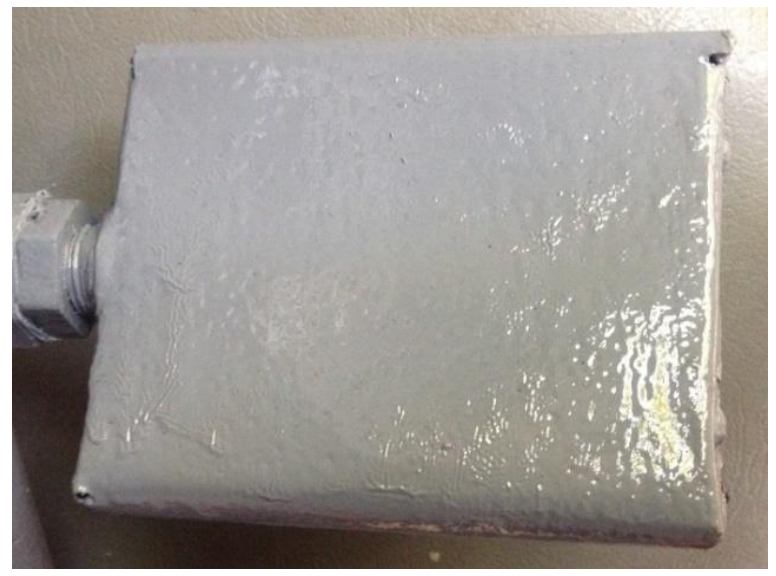

б)

Рис. 3. Лопасти, в которых размещен гибкий электрический нагревательный кабель: a) расположение нагревательного кабеля на лопасти; б) лопасть с установленным защитным кожухом. ${ }^{3}$

Для изготовления биогазового реактора использован стальной бак со следующими геометрическими параметрами: высота 0,6 м, діаметр $0,37 \mathrm{~m}$, объем $0,06 \mathrm{~m}^{3}$. Изоляция реактора выполнена из слоя минеральной ваты толщиной 100 мм. Для защиты изоляционного слоя от влаги и механических повреждений биогазовый реактор соосно размещен внутри стального бака большего диаметра.

Вал электротермомеханической системы 
смешения и нагрева выполнен из полой стальной трубы. Лопасти изготовлены из стальных пластин с внутренними канавками, в которые помещен гибкий нагревательный кабель из углеродного волокна.

Схема и номенклатура измерительного оборудования, используемого в экспериментальной установке биогазового реактора с электротермомеханической системой перемешивания и нагрева субстрата, в мае 2020 года была опубликована в материалах IX Международной научно-технической конференции «Проблемы современной энергетики и автоматизации в системе природопользования».

В обоих вариантах один и тот же режим перемешивания субстрата обеспечивался электродвигателем смесительного устройства. В качестве субстрата использовали предварительно измельченные картофельные остатки массой 10 кг, разбавленные 30 л чистой воды, и на 2/3 объема загружали в биогазовый реактор.

Экспериментальные исследования проводились в два этапа: на первом этапе исследование энергозатрат системы электрообогрева при размещении греющего кабеля на стенке реактора; на втором этапе при размещении греющего кабеля в лопастях мешалки. В обоих вариантах подготовленный субстрат загружали в биогазовый реактор и

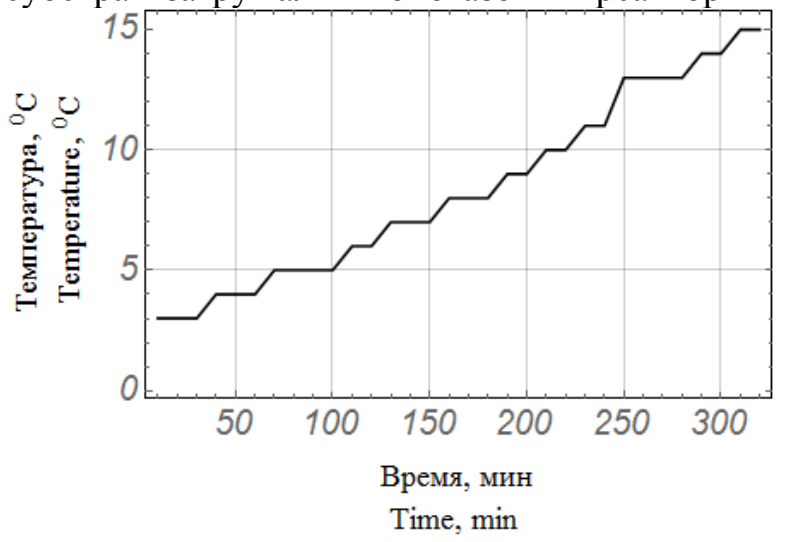

a) оставляли в нем на 12 часов для обеспечения температурного баланса всех объектов, контактирующих с субстратом. Затем включалась система электроснабжения установки, система автоматического управления и регистрации данных и проводились экспериментальные исследования энергозатрат. Эксперимент проводился в климатической зоне Украины, г. Киев.

Для измерения температуры нагревательного кабеля, субстрата и стенки реактора использовались цифровые датчики температуры DS18B20. Преобразование температуры происходит с точностью 12 бит, что соответствует точности измерения $0,0625^{\circ} \mathrm{C}$. Измерение тока, потребляемого электронагревателями и электродвигателем от сети, производится с помощью трансформаторов тока SCT-013-030 с погрешностью измерения $1 \%$. Датчики питаются от лабораторного блока питания PeakTech 6225A, погрешность выходного напряжения составляет $\leq 0,01 \% \pm 1 \mathrm{мB}$.

Показания измерительных датчиков регистрировались непрерывно и автоматически с помощью разработанной системы автоматического контроля и регистрации. Температурный режим экспериментов для двух этапов представлены на графиках изменения температуры окружающей среды (рис. 4).

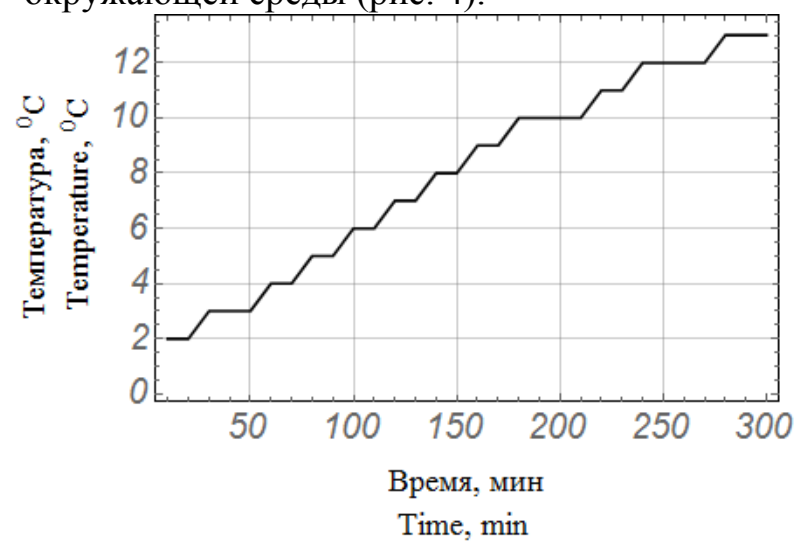

б)

Рис. 4. График изменения температуры окружающей среды при размещении электрического нагревательного кабеля соответственно: а) на стенке биогазового реактора; б) в лопастях мешалки. ${ }^{4}$

При начальном нагреве субстрата до температуры брожения при размещении электрического нагревательного кабеля на стенке биогазового реактора среднее значение температуры окружающей среды равно $8,37{ }^{\circ} \mathrm{C}$ (рис. 4 a), а среднее значение влажности окружающей среды 64,4\%. При размещении нагревательного кабеля в лопастях двухъярусной мешалки средняя температура окружающей среды составляет $8^{\circ} \mathrm{C}$ (рис. 4 б), а средняя влажность окружающей среды 70,2\%. 


\section{II. РЕЗУЛЬТАТЫ И ОБСУЖДЕНИЕ}

Сравнивая температурный режим опытов, отметим, что среднее значение температуры окружающей среды на первом этапе на 4,4 \% выше, чем при исследованиях второго этапа, когда нагревательный кабель монтируется в

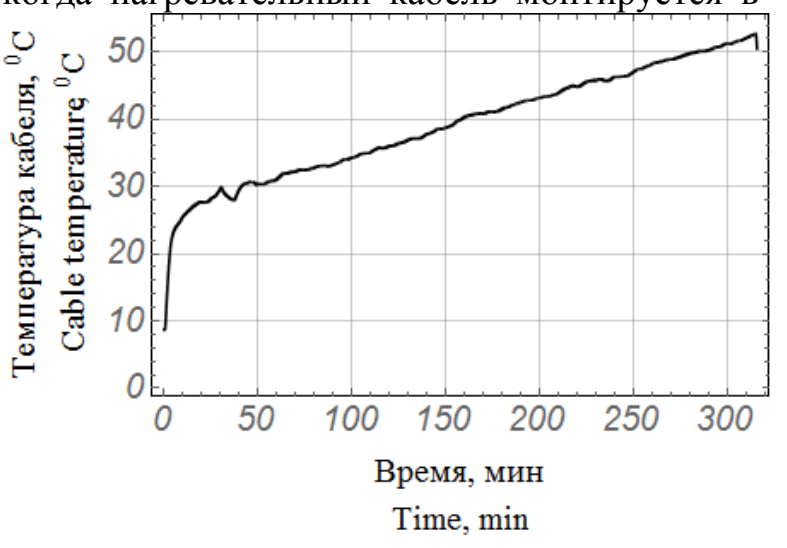

a) лопасти двухъярусной лопастной. мешалки. На рисунках 5-9 показаны изменения температуры электрического нагревательного кабеля, субстрата в нижней, средней и верхней частях реактора и стенки биогазового реактора соответственно.

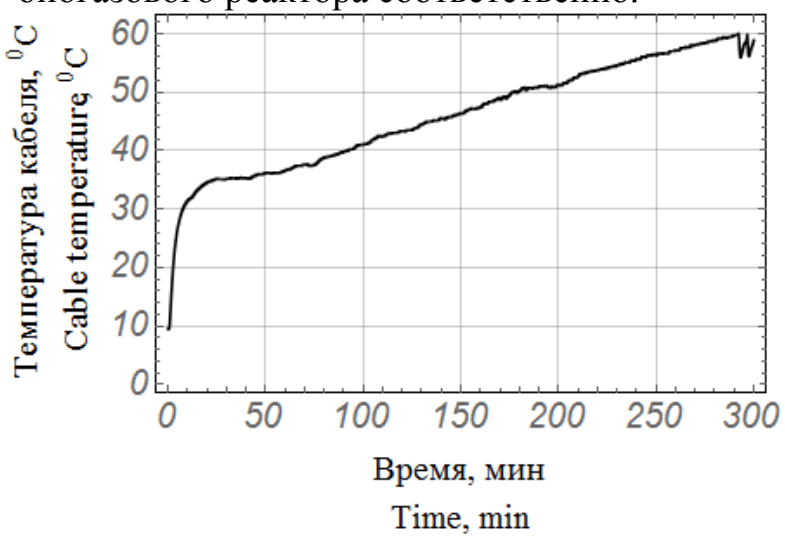

б)

\section{Рис. 5. График изменения температуры электрического нагревательного кабеля: а) при} размешении на стенке реактора; б) при размещении в лопастях мешалки. ${ }^{5}$

Анализируя график изменения температуры электрического нагревательного кабеля, расположенного на стенке реактора (рис. 5 а), заметно, что в течение первых 6 минут процесса нагрева наблюдается быстрый рост температуры от значения $9{ }^{\circ} \mathrm{C}$ до $23,8{ }^{\circ} \mathrm{C}$. Это связано с отсутствием установленного потока субстрата в биогазовом реакторе и аккумулированием тепловой энергии электрическим нагревательным кабелем, так как удельная теплоемкость кабеля меньше удельной теплоемкости материалов реактора и субстрата. После этого происходит постепенный рост температуры нагревательного кабеля, значение которой в момент $\Delta t=316$ мин, составляет $52,8^{\circ} \mathrm{C}$.

Средняя температура электрического нагревательного кабеля, уложенного на стенку реактора, составляет $39,24{ }^{\circ} \mathrm{C}$. Из графических зависимостей изменения температуры электрического нагревательного кабеля, помещенного в двухъярусную механическую лопастную мешалку (рис. 5 б), видно, что, в первые, 10 минут нагрева, температура быстро возрастает от $9{ }^{\circ} \mathrm{C}$ до $31,26^{\circ} \mathrm{C}$.

За период времени $\Delta t=25 \ldots 41$ мин (рис. 5 б), имеет место равномерная температура электрического нагревательного кабеля, значение которой равно $35{ }^{\circ} \mathrm{C}$, через 41 минуту после начала подогрева субстрата происходит постепенное повышение температуры электрического нагревательного кабеля до значения $60^{\circ} \mathrm{C}$. В момент времени $\Delta t=291 \quad$ мин, регулятор температуры срабатывает и отключает секцию электронагрева. В момент времени $\Delta t=293,5$ мин, температура электрического нагревательного кабеля составляет $56{ }^{\circ} \mathrm{C}$, затем подается питающее напряжение на секцию электрообогрева и температура кабеля начинает повышаться (рис. 5 б) и далее поддерживается термостатом в диапазоне $58-60^{\circ} \mathrm{C}$. Средняя температура электрического нагревательного кабеля, помещенного в лопасти двухъярусной лопастной механической мешалки, при начальном нагреве равна $46,04^{\circ} \mathrm{C}$.

Сравнивая две системы электрообогрева субстрата, расположенного в биогазовом реакторе, можно отметить, что для электрического нагревательного кабеля, размещенного в лопастях двухъярусной механической лопастной мешалки, его средняя и максимальная температуры выше на $15 \%$ и $12 \%$. соответственно, чем для электронагревательного кабеля, уложенного на стенку биогазового реактора. Достижение максимальной температуры нагревательного кабеля, помещенного в лопасти двухъярусной механической лопастной мешалки, происходит в среднем на 7,9 \% быстрее. 


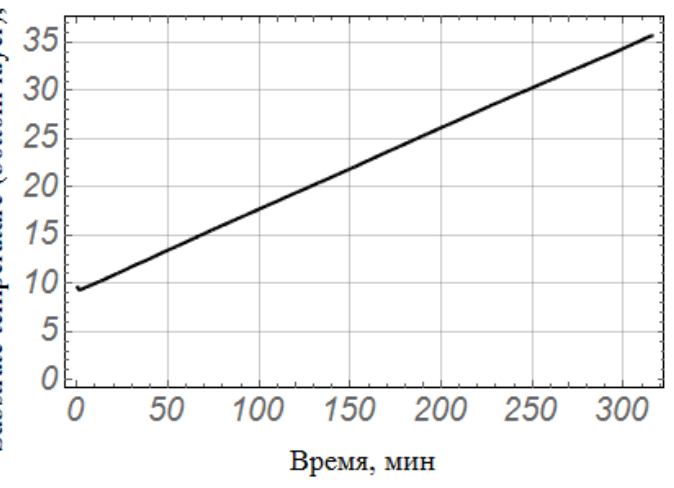

Time, $\min$

a)
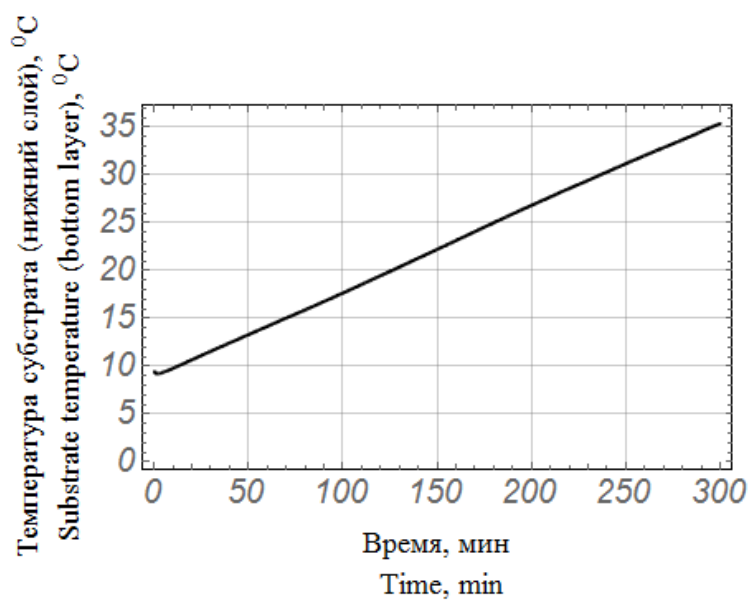

б)

Рис. 6. График изменения температуры субстрата в нижней части реактора при размещении электрического нагревательного кабеля соответственно: а) на стенке биогазового реактора; б) в лопастях мешалки.

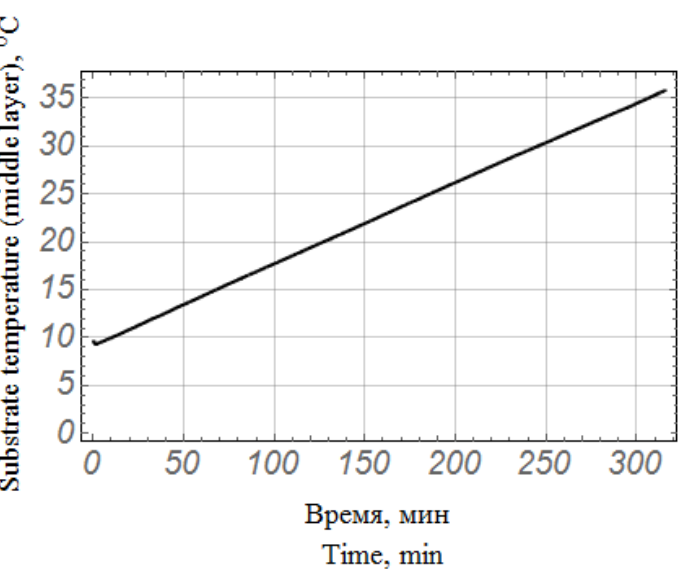

a)
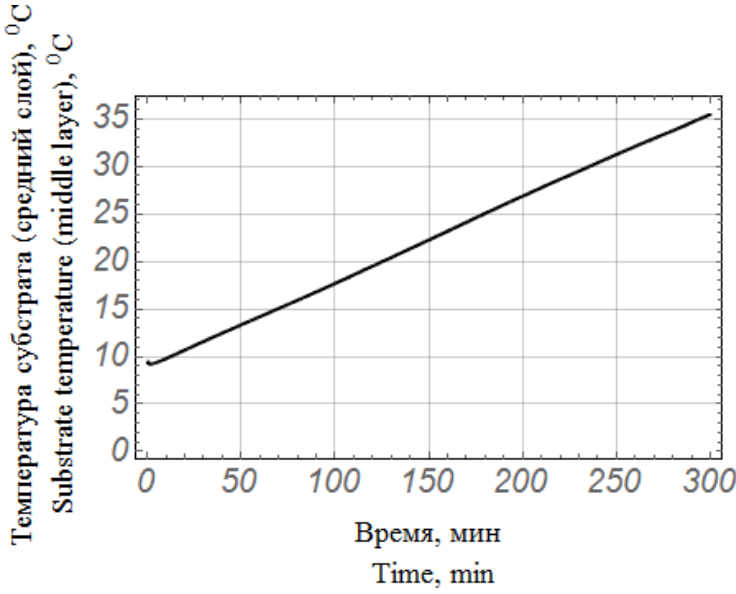

б)

Рис. 7. График изменения температуры субстрата в средней части реактора при размещении электрического нагревательного кабеля соответственно: а) на стенке биогазового реактора; б) в лопастях мешалки. ${ }^{7}$

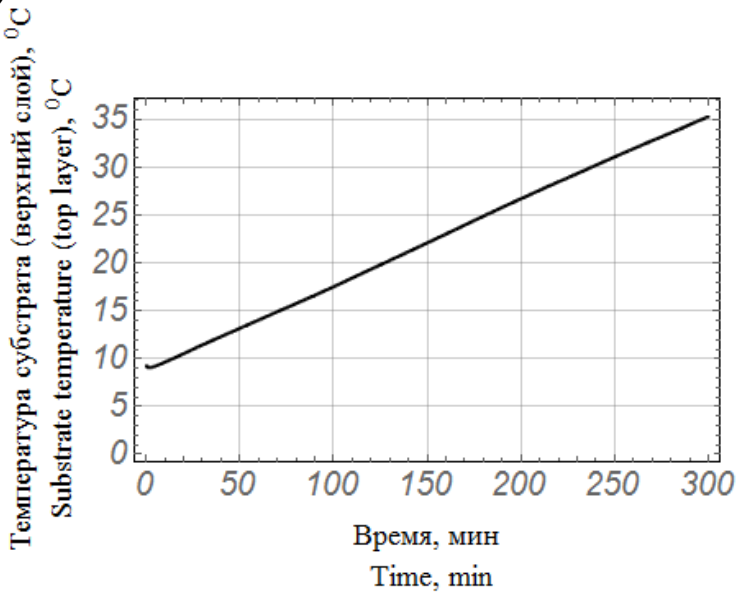

б)

Рис. 8. График изменения температуры субстрата в верхней части реактора при размешении электрического нагревательного кабеля соответственно: а) на стенке биогазового реактора; б) в лопастях мешалки. 
При размещении электронагревательного кабеля на стенке биогазового реактора из графических зависимостей изменения температуры субстрата в нижней (рис. 6 a), средней (рис. 7 a) и верхней (рис. 8 a) частях реактора видно, что начальная температура субстрата в реакторе составляет $9,5^{\circ} \mathrm{C}$.

В начальный момент перемешивания и нагревания происходит некоторое снижение температуры субстрата. Это объясняется процессом термодинамического равновесия, происходящим при установлении принудительного теплообмена в биогазовом реакторе.

Дальнейшее повышение температуры субстрата носит линейный характер.

В момент отключения системы подогрева субстрата $\Delta t=316$ мин, температура нижней части субстрата составляет $35,69{ }^{\circ} \mathrm{C}$, средней $-35,81^{\circ} \mathrm{C}$, верхней $-35,69^{\circ} \mathrm{C}$.

Среднее значение температуры субстрата равно $35,73^{\circ} \mathrm{C}$.

При размещении электронагревательного кабеля в лопастях двухъярусной механической мешалки из графических зависимостей изменения температуры субстрата в нижней (рис. 6 б), средней

$$
\text { O }
$$

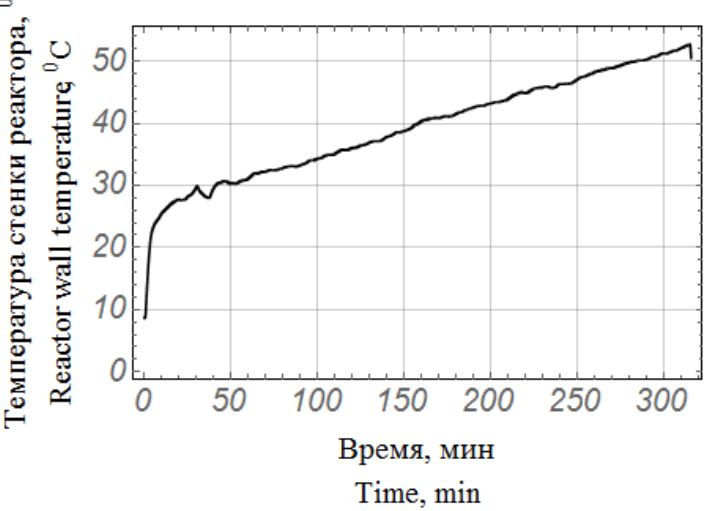

a) (рис. 7 б), верхней (рис. 8 б) части реактора видно, что начальная температура субстрата в объеме реактора составляет $9,3{ }^{\circ} \mathrm{C}$. Как и в предыдущем случае, в начальный момент перемешивания и нагревания субстрата происходит некоторое снижение температуры субстрата. Дальнейшее повышение температуры субстрата носит линейный характер.

В момент отключения системы подогрева субстрата $\Delta t=300$ мин, температура нижней части субстрата составляет $35,73{ }^{\circ} \mathrm{C}$, средней $-35,82^{\circ} \mathrm{C}$, верхней $-35,73{ }^{\circ} \mathrm{C}$.

Среднее значение температуры субстрата равно $35,76^{\circ} \mathrm{C}$.

При сравнении двух систем нагрева видно, что начальная температура субстрата при использовании системы нагрева, расположенной на стенке реактора, на $2 \%$ выше.

При этом время начального нагрева субстрата до температуры брожения с помощью электрических нагревателей, вмонтированных в лопасти механической двухступенчатой мешалки, меньше на 5 \%.

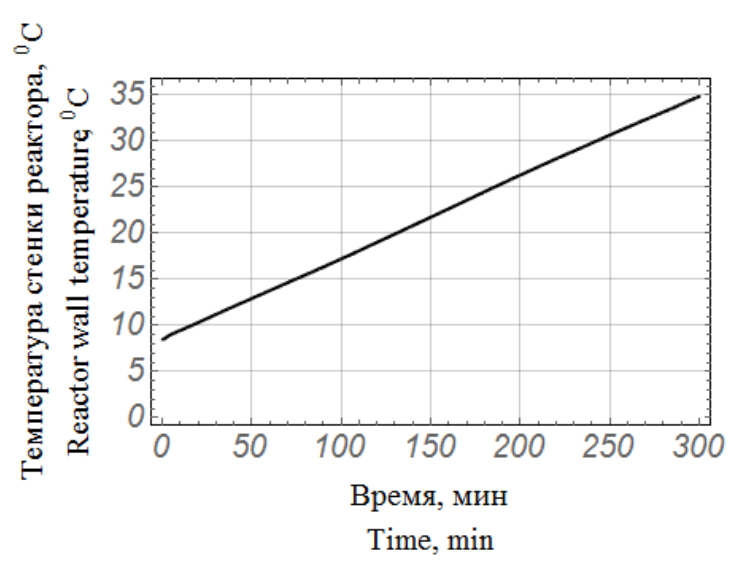

б)

Рис. 9. График изменения температуры стенки биогазового реактора при размещении электрического нагревательного кабеля соответственно: а) на стенке биогазового реактора; б) в лопастях мешалки. ${ }^{9}$

График изменения температуры стенки биогазового реактора при размещении электрического нагревательного кабеля на стенке биогазового реактора (рис. 9 а) показывает, что изменение температуры стенки аналогично графической зависимости изменения температуры электрического нагревательного кабеля (рис. 5 a).
Из графической зависимости (рис. 9 б) видно, что при использовании электрического нагревательного кабеля, расположенного в лопастях мешалки, температура стенки биогазового реактора изменяется так же, как и температура субстрата (рис. 7 б), однако, имея более низкое значение температуры на $0,7^{\circ} \mathrm{C}$. 


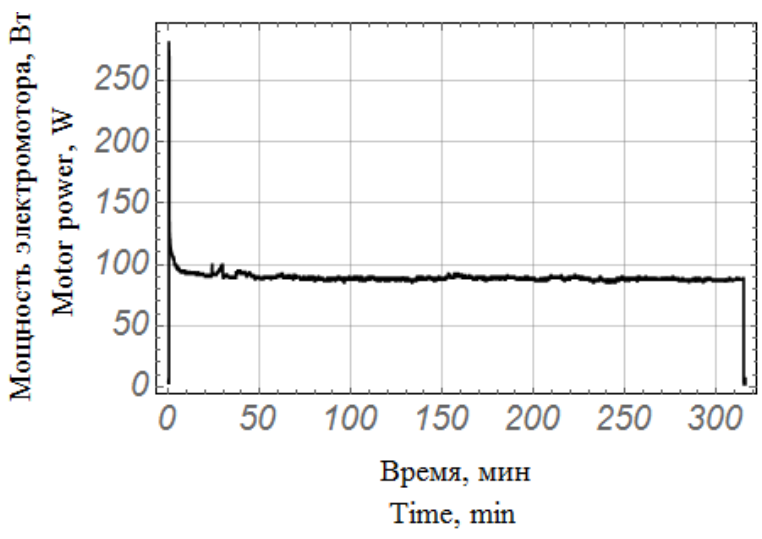

a)

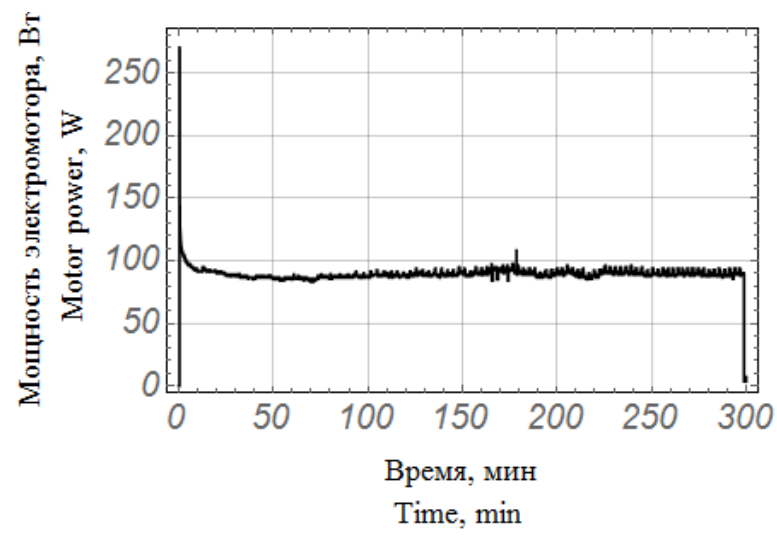

б)

Рис. 10. График потребления электроэнергии электродвигателем: а) при размещении электрического нагревательного кабеля на стене биогазового реактора; б) при размещении электрического нагревательного кабеля в лопастях мешалки. ${ }^{10}$

Анализируя графики потребления мощности электродвигателем (рис. 10 а) заметно, что в начальный момент движения происходит мгновенное увеличение мощности до значения 280 Вт, (рис. 10 а) вызванный вращающим моментом, с последующим выходом на номинальную мощность, среднее значение которой равно 90 Вт.

Продолжительность нагрева подложки до температуры $35,8{ }^{\circ} \mathrm{C}$, при размещении электронагревательного кабеля на стенке реактора составляет 316 минут. Электродвигатель перемешивающего устройства при использовании обогрева, расположенного на стенке реактора, потребляет $W_{l}=1,69 \cdot 10^{6}$ Дж на процесс начального нагрева субстрата до температуры брожения.

Из графической зависимости (рис. 10 б) видно, что при использовании электротермомеханической системы при размещении электрического нагревательного кабеля в лопастях мешалки в начальный момент движения за счет преодоления сопротивления лопастей которое создается субстратом происходит мгновенное увеличение мощности до значения 270 Вт. В дальнейшем происходит выход на номинальную мощность, среднее значение которой 90 Вт.

Электродвигатель смесительного устройства при использовании нагрева, размещенного в лопастях двухъярусной лопастной мешалки, потребляет $W_{1}=1,60 \cdot 10^{6}$ Дж, на процесс начального нагрева субстрата до температуры брожения.

Сравнивая две системы, можно утверждать, что при использовании электронагревателей, размещенных в лопастях двухъярусной лопастной механической мешалки, электродвигатель перемешивающего устройства потребляет на $5,3 \%$ меньше энергии на начальный нагрев субстрата до температуры брожения. При этом, продолжительность нагрева до температуры $35,8{ }^{\circ} \mathrm{C}$, при размещении электронагревательного кабеля в лопастях мешалки составляет 300 мин, что на 16 мин меньше, чем при системе обогрева на стенке реактора.

Анализируя графики потребления мощности электронагревательным кабелем (рис. 11 а), заметно, что при включении нагревателей происходит резкое увеличение мощности до значения 293 Вт и находится в пределах этого значения в течение всего пери ода подогрева.

Система обогрева выполнена из электрического нагревательного кабеля, размещенного на стенке биогазового реактора, потребляет $W_{2}=5,34 \cdot 10^{6}$ Дж, на процесс нагрева субстрата с $9,5{ }^{\circ} \mathrm{C}$ до $35,8^{\circ} \mathrm{C}$ (рис. 6 а, рис. 7 а, рис. 8 а). Среднее значение потребляемой мощности электрическими нагревателями составляет 281,75 Вт. 


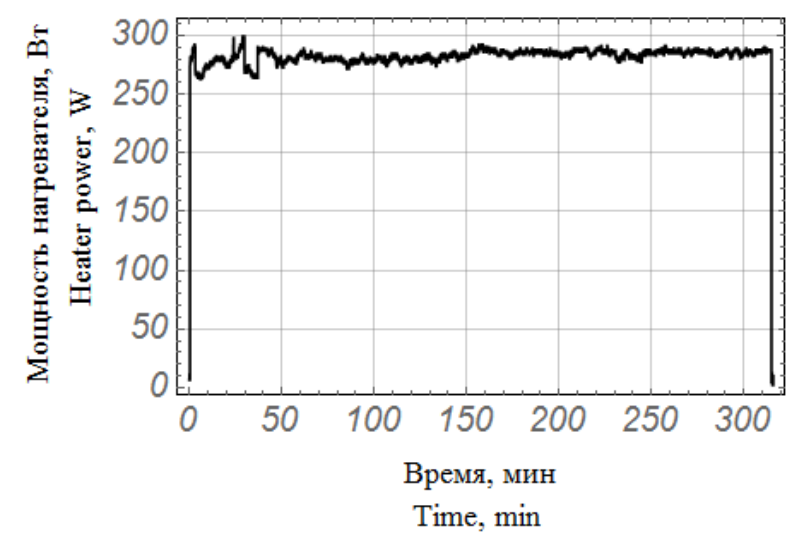

a)

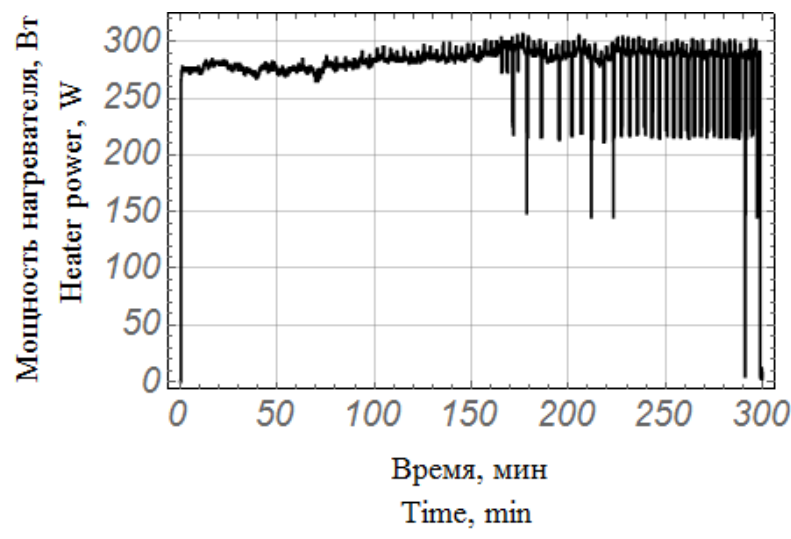

б)

Рис. 11. График потребления мощности электрическим нагревательным кабелем: а) при размещении электрического нагревательного кабеля на стене биогазового реактора; б) при размещении электрического нагревательного кабеля в лопастях мешалки. ${ }^{11}$

Из графических зависимостей (рис. 11 б) видно, что при использовании электротермомеханической системы при размещении электрического нагревательного кабеля в лопастях мешалки в момент включения нагревательных секций происходит резкое увеличение мощности на значение 278 Вт в дальнейшем увеличивается до значения номинальной мощности 293 Вт. В момент времени $\Delta t=172$ мин, происходит снижение потребляемой мощности электрическими нагревателями до величины 219 Вт. Это связано с достижением на участке нагрева температуры отключения. Аналогичная картина включениявыключения нагревательных секций, установленных в лопастях двухъярусной лопастной мешалки, наблюдается до полного отключения системы нагрева субстрата.

Система обогрева выполнена электрическим нагревательным кабелем, закрепленным в лопастях двухъярусной лопастной мешалки, потребляет $W_{2}=4,99 \cdot 10^{6}$ Дж, для процесса нагрева субстрата в биогазовом реакторе с $9,3{ }^{\circ} \mathrm{C}$ до $35,8^{\circ} \mathrm{C}$ (рис. 6 б, рис. 7 б, рис. 8 б). Среднее значение потребляемой мощности нагревателями составляет 277,4 Вт.

Сравнивая две системы, заметно, что при использовании электрических нагревателей, размещенных в лопастях двухъярусной лопастной механической мешалки, система нагрева в среднем потребляет на 6,6 \% меньше энергии на начальный нагрев субстрата до температуры брожения.

Согласно информации, приведенной в [5, 6], многим странам мира приходится разрабатывать схемы государственной поддержки развития технологий возобновляемой энергетики. $\mathrm{C}$ учетом результатов, полученных в ходе ранее проведенных теоретических и нынешних экспериментальных исследований, заметно, что при использовании электротермомеханической системы перемешивания и нагрева субстрата, оба процесса интенсификации потребляют в среднем на 11,9 \% меньше энергии.

\section{III. ВЫВОДЫ}

1. Результаты экспериментальных исследований необходимого количества энергии на процесс начального нагрева субстрата до температуры сбраживания показали, что при использовании электрического нагревательного кабеля вмонтированного в лопасти мешалки процесс начального нагрева субстрата объемом 40 литров к температуре сбраживания происходит быстрее в среднем на 16 минут.

2. Установлено, что максимальное значение температуры электрического нагревательного кабеля, размещенного в лопастях мешалки, в среднем на $12 \%$ выше по сравнению с температурой электрического нагревательного кабеля, размещенного на стенке реактора. Также, установлено, что средняя температура электронагревательного кабеля, помещенного в лопасти двухъярусной лопастной мешалки, в среднем выше на $15 \%$.

3. Установлено, что использование нагревательного кабеля в сочетании с механической мешалкой снижает количество энергии, затрачиваемой на процесс начального нагрева субстрата до температуры 
брожения, и согласно 3 повторениям исследований, находиться в диапазоне 5,8$7,4 \%$. В результате, среднее значение затраченой энергии на подогрев, составляет 6,6\% для субстрата объемом 40 литров.

4. На процесс перемешивания субстрата в биогазовом реакторе емкостью 40 литров расходуется меньше энергии в диапазоне 4,7$5,9 \%$, что в среднем составляет $5,3 \%$.

5. Данные, представленные в статье, могут быть использованы при проектировании и модернизации систем перемешивания и нагрева субстрата в биогазовых реакторах.

\section{Appendix 1}

${ }^{1}$ Fig. 1. Appearance of the experimental biogas plant.

${ }^{2}$ Fig. 2. Electric heating cable laid on the outer wall of the biogas reactor.

${ }^{3}$ Fig. 3. Paddles in which the electric flexible heating cable is placed: a) location of the heating cable on the paddle; b) paddle with an installed protective cover.

${ }^{4}$ Fig. 4. Ambient temperature curve when placing an electric heating cable, respectively: a) on the wall of the biogas reactor; b) in the paddles of the stirrer.

${ }^{5}$ Fig. 5. The electric heating cable temperature curve: a) when mounted on the biogas reactor walls; b) when mounted in the stirrer paddles.

${ }^{6}$ Fig. 6. The substrate temperature change in the lower part of the reactor with the electric heating cable, mounted, respectively: a) on the wall of the biogas reactor; b) in the paddles of the stirrer.

${ }^{7}$ Fig. 7. The substrate temperature change in the middle part of the reactor with the electric heating cable, mounted respectively: a) on the wall of the biogas reactor; $b$ ) in the paddles of the stirrer.

${ }^{8} \mathbf{F i g}$. 8. Graph of substrate temperature change in the upper part of the reactor with the electric heating cable mounted, respectively: a) on the wall of the biogas reactor; $b$ ) in the paddles of the stirrer.

${ }^{9}$ Fig. 9. The temperature change curve of the wall of the biogas reactor with the electric heating cable mounted, respectively: a) on the wall of the biogas reactor; $b$ ) in the paddles of the stirrer.

${ }^{10}$ Fig. 10. The power consumption curve of the electric motor: a) with the electric heating cable mounted on the wall of a biogas reactor; $b$ ) with the electric heating cable mounted in the paddles of the stirrer.

${ }^{11}$ Fig. 11. The power consumption curve of the electric heating cable: a) with the electric heating cable mounted on the wall of a biogas reactor; $b$ ) with the electric heating cable mounted in the paddles of the stirrer.

\section{Библиография (References)}

[1] Albertson M.L., Pruden A., Oliver R.T. Enhanced anaerobic digestion of biomass waste for optimized production of renewable energy and solids for compost. Int. Congr. Sci. 2006, 1293, pp. 221-229.

[2] Ch. McCombie, M. Jefferson. Renewable and nuclear electricity: Comparison of environmental impacts, Energy Policy, 2016, no. 96, pp. 758-769.

[3] D. Weisser. A guide to life-cycle greenhouse gas (GHG) emissions from electric supply technologies, Energy, 2007, no. 32, pp. 1543-1559.

[4] IEA Statistics, 2016.

[5] D.-A. Ciupăgeanu, G. Lăzăroiu, M. Tîrşu, Carbon dioxide emissions reduction by renewable energy employment in Romania, 2017 International Conference on Electromechanical and Power Systems (SIELMEN), 2017, pp. 281-285, doi: 10.1109/SIELMEN.2017.8123333.

[6] G. Dragomir, A. Şerban, G. Năstase, A.I. Brezeanu. Wind energy in Romania: A review from 2009 to 2016, Renewable and Sustainable Energy Reviews, 2016, no. 64, pp. 129-143.

[7] Baader V., Donet E., Brennderfer M. Biogas. Theory and practice. $1982,148 \mathrm{p}$.

[8] Marks, S., Dach, J., Fernandez Morales, F.J., Mazurkiewicz, J., Pochwatka, P., Gierz, Ł. (2020). New Trends in Substrates and Biogas Systems in Poland. Journal of Ecological Engineering, 2020, vol. 21, no. 4, pp. 19-25. DOI: /10.12911/22998993/119528.

[9] Balussou D,. McKenna R., Möst D. Fichtner W. A model-based analysis of the future capacity expansion for German biogas plants under different legal frameworks. Renew. Sustain. Energy Rev. 2018, no. 96, pp. 119-131.

[10] EBA. EBA Statistical Report 2018; European Biogas Association: Brussels, Belgium, 2019.

[11] WBA. Global Potential of Biogas; World Biogas Association: London, UK, 2019.

[12] Deublein D., Steinhauser A. Biogas from Waste and Renewable Resources. An Introduction. KGaA, Weinheim, 2008, p. 450.

[13] Ward A.J., Hobbs P.J., Holliman P.J., Jones D.L. Optimisation of the anaerobic digestion of agricultural resources. Bioresour. Technol. 2008, no. 99. pp. 7928-7940.

[14] Latha K., Velraj R., Shanmugam P. Sivanesan S. Mixing strategies of high solids anaerobic co-digestion using food waste with sewage sludge for enhanced biogas production. J. Clean. Prod. 2019, no. 210, pp. 388-400.

[15] Ameur H. Mixing of complex fluids with flat 
and pitched bladed impellers: effect of blade attack angle and shear-thinning behavior. Food Bioprod. Process. 2016, no. 99, pp. 71-77.

[16] Foukrach M., Bouzit M., Ameur H. Effect of Agitator's Types on the Hydrodynamic Flow in an Agitated Tank. Chin. J. Mech. Eng. 2020, no. 33, 37 p. doi: 10.1186/s10033-020-00454-2.

[17] Trad Z., Fontaine J., Larroche C., Vial C. Multiscale mixing analysis and modeling of biohydrogen production by dark fermentation. Renew. Energy 2016 , no. 98 , pp. 264-282.

[18] Ameur H. Modifications in the Rushton turbine for mixing viscoplastic fluids. J. Food Eng. 2018, no. 223, pp. 117-125.

[19] Scarlat N., Dallemand J.-F., Fahl F. Biogas: Developments and perspectives in Europe. Renew. Energy 2018, no. 129, pp. 457-472.

[20] Janczak D., Mazurkiewicz J., Czekała W., Myszura M., Kozłowski K., Jeżowska A. A Possibility of Functioning Biogas Plant at a Poultry Farm.
Journal of Ecological Engineering, 2019, vol. 20, no. 11, pp. 225-231.

[21] Marks S., Jeżowska A., Kozłowski K., Dach J., Wilk B., Fudala-Książek S. Review of mixing systems of fermentation liquid used in biogas plants. Technika Rolnicza Ogrodnicza Leśna, 2017, no. 6, pp. 24-26.

[22] Pham C.H., Vu C.C., Sommer S.G., Bruun S. Factors Affecting Process Temperature and Biogas Production in Small-scale Rural Biogas Digesters in Winter in Northern Vietnam. 2014, vol. 27, no.7, pp. 1050-1056.

[23] Rashed M. B. The Effect of Temperature on the biogas Production from Olive Pomace. University Bulletin ISSUE. 2014, vol. 3, no. 16 pp. 135-148.

[24] Teleszewski T. J., Zukowski M. Analysis of Heat Loss of a Biogas Anaerobic Digester in Weather Conditions in Poland. Journal of Ecological Engineering, 2018, vol. 19, no. 4, pp. 242-250.

\section{Сведения об авторах.}

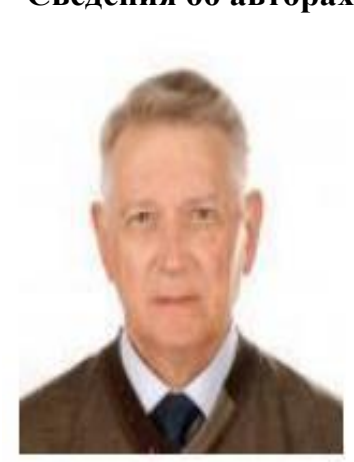

Заблодский Николай

Николаевич. Национальный университет биоресурсов и природопользования

Украины. Заместитель директора института энергетики, автоматики и энергосбережения, доктор технических наук, профессор. Основная область

исследований: технологии конверсии биомассы в высококачественный биогаз по сокращенной ферментации под воздействием электромагнитного поля, переработка побочных продуктов птицеводства в топливо, биологические корма и удобрения.

E-mail: zablodskiynn@gmail.com

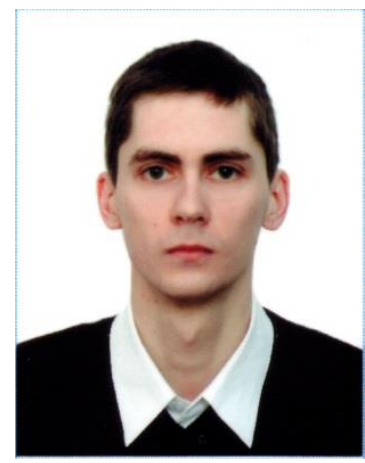

Сподоба

Михаил

Алексеевич. Национальный университет биоресурсов и природопользования

Украины, кафедра электротехники,

электромеханики

электротехники, аспирант.

Основная область

исследований:

Энергоэффективность

технологических процессов производства, легкой и тяжелой промышленности. E-mail: spmisha@ukr.net

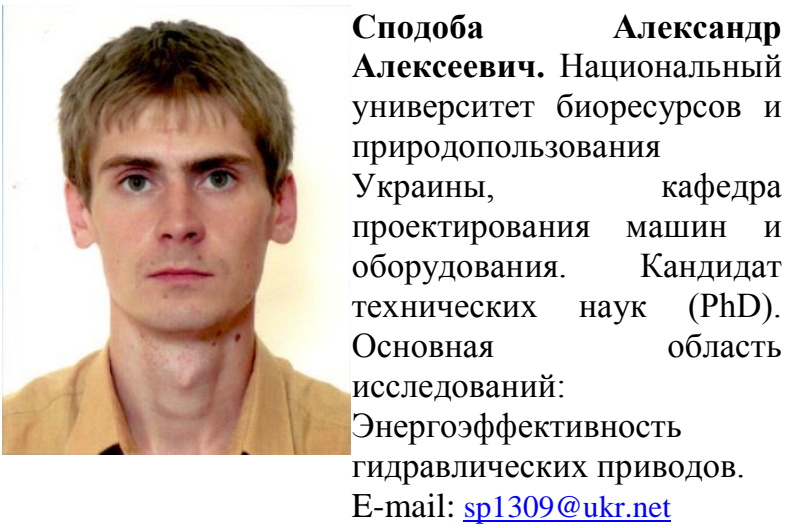

Сподоба Александр

Алексеевич. Национальный университет биоресурсов и природопользования

Украины, кафедра проектирования машин и оборудования. Кандидат технических наук (PhD). Основная область исследований: гидравлических приводов. E-mail: sp1309@ukr.net 